\title{
Aortic balloon occlusion simplifies dissected thoracoabdominal aortic aneurysm repair after frozen elephant trunk
}

Jinlin $\mathrm{Wu}^{1}$, JUE YANG ${ }^{1}$, Changjiang $\mathrm{Yu}^{1}$, Jun $\mathrm{Ke}^{1}$, Zhongmin $\mathrm{Cao}^{1}$, Yangfen Wu ${ }^{1}$, Ruixin Fan $^{1}$, Tucheng Sun ${ }^{1}$, and Xin $\mathrm{Li}^{1}$

${ }^{1}$ Guangdong Provincial People's Hospital

February 9, 2022

\begin{abstract}
Here, we report a case of a dissected thoracoabdominal aortic aneurysm repair after frozen elephant trunk implantation, using aortic balloon occlusion technique to simplify the proximal anastomosis and avoid deep hypothermic circulatory arrest. In addition, detailed CT follow-up pictures showed that false lumen thrombosis is a time-dependent and reversible variable. Repeated measurements with time series analysis should be performed to explore false lumen remodeling.
\end{abstract}

\section{Hosted file}

manuscript20210928.docx available at https://authorea.com/users/421113/articles/555874aortic-balloon-occlusion-simplifies-dissected-thoracoabdominal-aortic-aneurysm-repairafter-frozen-elephant-trunk 

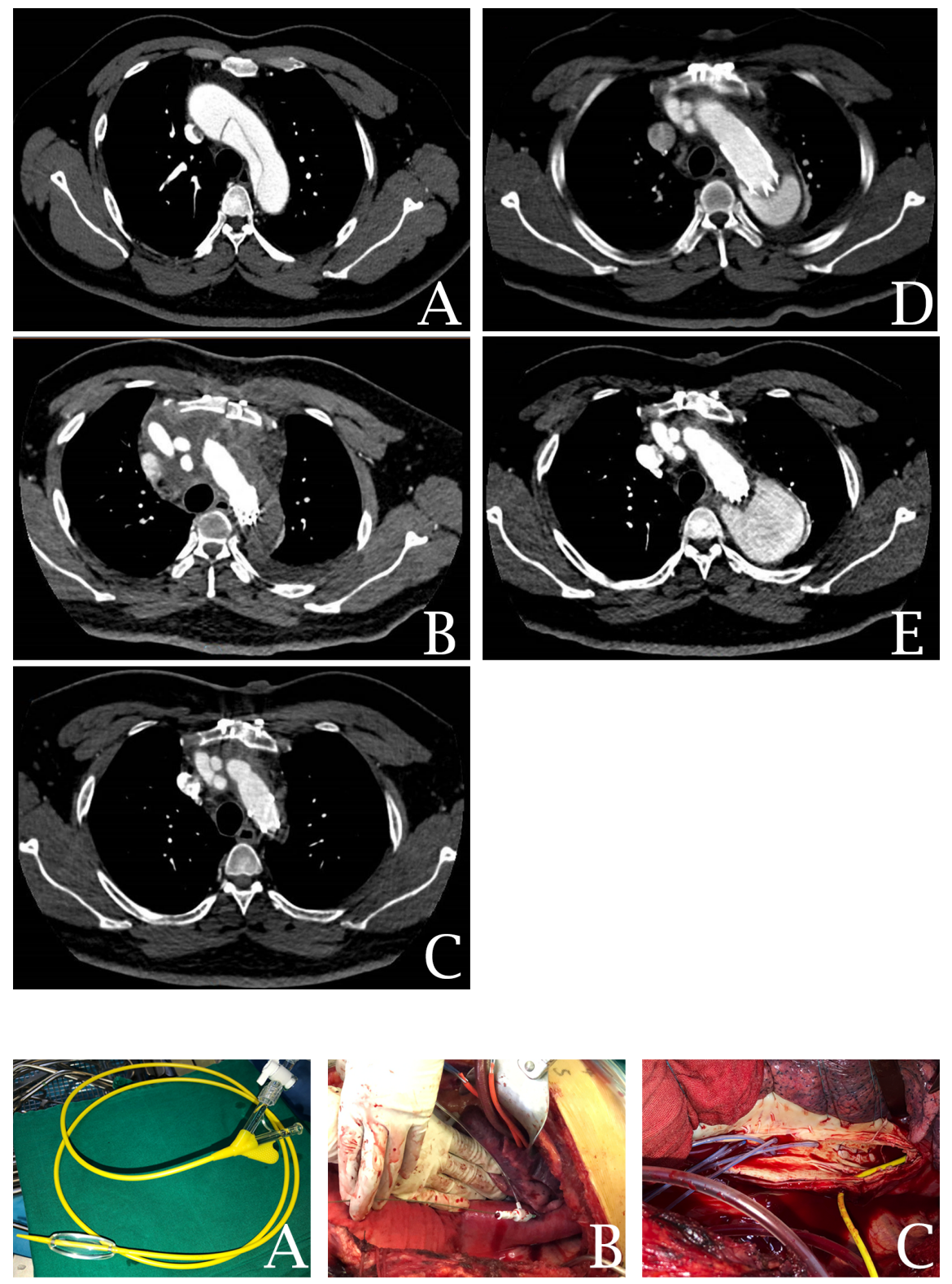